\title{
KUALITAS TIDUR PASIEN GAGAL JANTUNG DAN PENANGANANNYA
}

\author{
*Inggriane Puspita Dewi \\ *STIKES ‘Aisyiyah Bandung \\ Jl. KH. Ahmad Dahlan Dalam No. 6 Bandung 40264 \\ Telp. (022) 7305269, 7312423 - Fax. (022) 7305269 \\ Email: ine.stikes12@gmail.com
}

\begin{abstract}
Abstrak
Prevalensi gagal jantung meningkat seiring dengan usia, dan mempengaruhi 6-10\% individu lebih dari 65 tahun. Penderita gagal jantung sering mengalami hipersomnia di siang hari, tetapi kurang tidur atau sering terbangun dari tidur di malam hari karena sesak. Gangguan tidur ini dapat berupa SDB (sleep disordered breathing), DMS (difficulties maintaining sleep) dan EDS (excessive daytime sleepiness) lebih sering terjadi pada lansia dengan gagal jantung. Literature review ini bertujuan untuk menemukan bukti-bukti (evidence) kualitas tidur pada pasien gagal jantung serta penanganannya. Studi literatur dari beberapa jurnal yang bersumber dari medline, dengan kata kunci Sleep Quality dan Heart Failure, sebanyak 5 jurnal dipilih untuk direview. Hasilnya adalah kekurangan tidur pada penderita gagal jantung berdampak terhadap kualitas hidupnya, cenderung menderita depresi yang berdampak terhadap peningkatan kematian, sudden cardiac death dan ventrikuler aritmia. Penanganan berupa terapi farmakologis dan non farmakologis. Implikasi terhadap ilmu keperawatan dari masalah kualitas tidur pasien gagal jantung, diupayakan mengembangkan model terapi regimen non farmakologi, dengan mempertimbangkan aspek psikososial dan spiritual.
\end{abstract}

Kata kunci : kualitas tidur, kualitas hidup, regimen terapi non farmakologis

\begin{abstract}
The prevalence of heart failure increases with age and affects 6-10\% of individuals over 65 years. Patient with heart failure often experience hypersomnia during the day, but lack of sleep or frequent walking from sleep at night because of shortness of sleep. SDB (Sleep Disordered Breathing), DMS (Difficulties Maintaining Sleep) and EDS (Excessive Daytime Sleepiness) is more common in the elderly with heart failure. Literature review aims to find evidence based the quality of sleep in patients with heart failure and the treatment. Study of literature of several journals sourced from MEDLINE, the keyword Sleep Quality and Heart Failure, as much as 5 journals selected for review. Lack of sleep in patients with heart failure have an impact on quality of life, tend to suffer from depression which resulted in increased mortality, sudden cardiac death and ventricular arrhythmia. The treatment included the form of pharmacological and non-pharmacological therapies. Implications for nursing science of sleep quality problem of heart failure patients, strived to develop models of non-pharmacological treatment regimens, taking into account the psychosocial and spiritual aspects.
\end{abstract}

Keywords: quality of sleep, quality of life, non-pharmacological treatment regimen 


\section{PENDAHULUAN}

Penyakit Gagal Jantung yang dalam istilah medisnya disebut dengan "Heart Failure atau Cardiac Failure", merupakan suatu keadaan darurat medis dimana jumlah darah yang dipompa oleh jantung seseorang setiap menitnya tidak mampu memenuhi kebutuhan normal metabolisme tubuh (Suzuki, et al., 2008). Penderita gagal jantung di masyarakat memiliki tingkat kematian yang tinggi baik dengan EF (Ejection Fraction) yang stabil atau menurun. Namun resiko kematian lebih rendah pada gagal jantung dengan EF yang stabil dibandingkan pada penderita gagal jantung dengan EF yang menurun (Henkel, Redfield, Weston, Gerber, \& Roger, 2008).

Penderita gagal jantung sering mengalami hipersomnia di siang hari, tetapi kurang tidur atau sering terbangun dari tidur di malam hari karena sesak. Gangguan tidur ini dapat berupa SDB (sleep disordered breathing), DMS (difficulties maintaining sleep) dan EDS (excessive daytime sleepiness) lebih sering terjadi pada lansia dengan gagal jantung (Johansson et al. 2010). SDB yang parah dikaitkan dengan penurunan fungsi fisik pada pasien dengan gagal jantung yang stabil (Redeker et al. 2010). Kekurangan tidur berdampak terhadap kualitas hidupnya, sehingga pasien cenderung menderita depresi yang berdampak terhadap peningkatan kematian, sudden cardiac death dan ventrikuler aritmia (Thomas et al. 2008).

\section{Tujuan}

\section{Tujuan Umum}

Review literatur ini adalah untuk menemukan bukti-bukti (evidence) kualitas tidur pada pasien gagal jantung.

\section{Tujuan Khusus}

1. Menemukan patofisiologi penyakit dan dampaknya terhadap kualitas tidur

2. Menemukan temuan baru tentang penanganan masalah tidur pada pasien gagal jantung

\section{METODE PENELITIAN}

Beberapa literatur didapatkan dari database yang terdapat di Medline Research untuk kualitas tidur pasien dengan gagal jantung, patofisiologi dan penanganan yang dilakukan sejak tahun 2010 s.d. 2015, dengan menggunakan keyword: sleep quality and heart failure, didapatkan 137 hasil penelitian, namun hanya beberapa jurnal saja yang direview.

Tabel 1.

Berbagai Hasil Penelitian tentang Kualitas Tidur Pasien Gagal Jantung

\begin{tabular}{cllll}
\hline No & \multicolumn{1}{c}{ Judul-Penulis } & \multicolumn{1}{c}{ Sampel } & \multicolumn{1}{c}{ Metoda } & \multicolumn{1}{c}{ Hasil } \\
\hline 1 & Wang, T., Lee, S., & 101 pasien dengan & Analysis; Questionnaire & Pasien dengan gagal jantung harus \\
& Tsay, S., \& Tung, H. & gagal jantung dari & s; Scales; Self & diedukasi tentang Sleep Hygiene dan \\
& (2010). Factors & klinik kardiologi di & Report; Step-Wise & meningkatkan kegiatan rekreasi, \\
& influencing heart & Taiwan & Multiple & manajemen penyakitnya, dan \\
failure patients' sleep & & Regression; Summated & keterampilan penyesuaian emosional \\
& quality. Journal of & & Rating Scaling; T- & untuk meningkatkan kualitas tidur \\
Advanced Nursing $(J$ & & Tests; Taiwan; Test- & mereka. Pasien-pasien ini juga harus \\
& ADV NURS), 66(8), & & Retest Reliability & diamati untuk risiko kecelakaan/injury \\
& 1730-1740 & & waktu malam karena nokturia. \\
\hline 2 & Redeker, N., \& & 61 pasien dengan & Responden dipasang & Kualitas tidur berubah dipengaruhi oleh \\
& Hilkert, R. (2010 ). & gagal jantung yang & alat di pergelangan & seringnya terbangun di malam hari, \\
& Sleep and quality of & stabil & tangan untuk merekam & kinerja fungsional dan kesehatan mental \\
life in stable heart & & tidur malam hari dan & pada pasien gagal jantung dengan \\
\hline
\end{tabular}




\begin{tabular}{|c|c|c|c|c|}
\hline & $\begin{array}{l}\text { failure. } J A d v \text { Nurs., } \\
66(8), 1730-1740 .\end{array}$ & & $\begin{array}{l}\text { aktivitas sehari-hari } \\
\text { selama } 3 \text { hari di rumah, } \\
\text { dan mengisi kuisioner } \\
\text { Sleep Indeks Kualitas } \\
\text { Pittsburgh. }\end{array}$ & $\begin{array}{l}\text { sistolik stabil. Penanganan yang efektif } \\
\text { dari masalah tidur ini dapat } \\
\text { menyebabkan peningkatan kualitas } \\
\text { hidup }\end{array}$ \\
\hline 3 & $\begin{array}{l}\text { Liu, Ju-Chi, Hung, } \\
\text { Hsiang-Lien, Shyu, } \\
\text { Yuh-Kae, .. Pei- } \\
\text { Shan. (2011 ). The } \\
\text { impact of sleep } \\
\text { quality and daytime } \\
\text { sleepiness on global } \\
\text { quality of life in } \\
\text { community-dwelling } \\
\text { patients with heart } \\
\text { failure. Journal of } \\
\text { Cardiovascular } \\
\text { Nursing 26(2), 99- } \\
\text { 105. }\end{array}$ & $\begin{array}{l}88 \text { pasien dengan } \\
\text { penyakit jantung } \\
\text { yang stabil }\end{array}$ & cross-sectional study & $\begin{array}{l}\text { Temuan dari studi ini menambah bukti } \\
\text { bahwa pada orang dengan gagal jantung } \\
\text { yang stabil memiliki kualitas tidur yang } \\
\text { buruk, dan mempengaruhi persepsi diri } \\
\text { serta kualitas hidup, khususnya domain } \\
\text { fisik dan psikologis. }\end{array}$ \\
\hline 4 & $\begin{array}{l}\text { Herrscher, Akre, } \\
\text { Overland, Sandvik, \& } \\
\text { Westheim. (2014). } \\
\text { Clinical predictors of } \\
\text { sleep apnoea in heart } \\
\text { failure outpatients. } \\
\text { International Journal } \\
\text { Of Clinical Practice, } \\
68(6), 728-730 .\end{array}$ & $\begin{array}{l}115 \text { pasien dengan } \\
\text { teknik konsekutif }\end{array}$ & $\begin{array}{l}\text { dilakukan pengambilan } \\
\text { data di rumah pasien } \\
\text { meliputi data kebiasaan } \\
\text { tidur di rumah, } \\
\text { karakteristik klinis, } \\
\text { sampel darah, kebiasaan } \\
\text { mengantuk di siang } \\
\text { hari dan kualitas hidup } \\
\text { lainnya. }\end{array}$ & $\begin{array}{l}\mathrm{BMI} \geq 30 \mathrm{~kg} / \mathrm{m}^{2} \text { dikaitkan dengan } \\
\text { sedang sampai berat SDB (sleep } \\
\text { disordered breathing), sleep apnea } \\
\text { atau DMS (difficulties maintaining } \\
\text { sleep ). Dengan demikian, BMI dapat } \\
\text { digunakan sebagai salah satu kriteria } \\
\text { seleksi untuk rujukan pasien gagal } \\
\text { jantung ke spesialis tidur. }\end{array}$ \\
\hline 5 & $\begin{array}{l}\text { Suna, Mudge, } \\
\text { Stewart, Marquart, } \\
\text { O'Rourke, \& A;, S. } \\
\text { (2015). The effect of a } \\
\text { supervised exercise } \\
\text { training programme } \\
\text { on sleep quality in } \\
\text { recently discharged } \\
\text { heart failure patients. } \\
\text { European Journal Of } \\
\text { Cardiovascular } \\
\text { Nursing, 14 (3), 198- } \\
\text { 205 }\end{array}$ & $\begin{array}{l}\text { Uji eksperimen } n= \\
54\end{array}$ & $\begin{array}{l}\text { Responden adalah } \\
\text { pasien dengan sakit } \\
\text { gagal jantung, dipilih } \\
\text { secara acak dalam } \\
\text { waktu } 12 \text { minggu untuk } \\
\text { latihan olahraga atau } \\
\text { program yang sama } \\
\text { dengan dua kali } \\
\text { seminggu secara } \\
\text { terstruktur (n = 54). } \\
\text { Olahraga terdiri dari } \\
\text { dua sesi pelatihan } \\
\text { aerobik dan latihan } \\
\text { resistensi diawasi satu } \\
\text { jam, oleh seorang } \\
\text { spesialis olahraga. Hasil } \\
\text { utama adalah perubahan } \\
\text { Pittsburgh Sleep } \\
\text { Kualitas Index (PSQI) } \\
\text { digunakan untuk } \\
\text { kuisioner kualitas tidur }\end{array}$ & $\begin{array}{l}45 \% \text { dari peserta melaporkan tidur yang } \\
\text { buruk (PSQI } \geq 5 \text { ). PSQI skor global } \\
\text { meningkat secara signifikan lebih pada } \\
\text { kelompok yang melakukan olahraga } \\
\text { daripada kelompok kontrol (-1.5 } \pm 3,7 \\
\text { vs } 0,4 \pm 3,8, \mathrm{p}=0,03 \text { ). Peningkatan } \\
\text { kualitas tidur berkorelasi dengan } \\
\text { kapasitas latihan yang ditingkatkan dan } \\
\text { mengurangi gejala depresi, tetapi tidak } \\
\text { berpengaruh dengan perubahan indeks } \\
\text { massa tubuh atau denyut jantung. } \\
\text { Kesimpulan: waktu training selama } 12 \\
\text { minggu, dengan frekuensi latihan dua } \\
\text { kali seminggu dapat meningkatkan } \\
\text { kualitas tidur pasien dengan gagal } \\
\text { jantung. }\end{array}$ \\
\hline
\end{tabular}




\section{HASIL PENELITIAN}

Hasil literature review berdasarkan kelima jurnal diatas, dapat ditemukan beberapa hal penting terkait kualitas tidur pasien dengan gagal jantung. Secara garis besar ditemukan tentang hubungan penyakit gagal jantung dan pengaruhnya terhadap kualitas tidur pada jurnal yang ditulis oleh (Herrscher, Akre, Overland, Sandvik, \& Westheim, 2014; Liu et al., 2011; Redeker \& Hilkert, 2010), sementara mengenai penanganan masalah tidur pada pasien dengan gagal jantung dikemukakan (Suna et al., 2015; Wang, Lee, Tsay, \& Tung, 2010).

Perjalanan penyakit gagal jantung diawali dengan adanya faktor risiko. Faktor risiko koroner seperti diabetes dan merokok merupakan faktor yang dapat berpengaruh pada perkembangan dari gagal jantung. Selain itu berat badan serta tingginya rasio kolesterol total dengan kolesterol HDL juga dikatakan sebagai faktor risiko independen perkembangan gagal jantung. Gagal jantung terjadi karena interaksi kompleks antara faktor-faktor yang mempengaruhi kontraktilitas, after load, preload, atau fungsi lusitropik (fungsi relaksasi) jantung, dan respons neurohormonal dan hemodinamik yang diperlukan untuk menciptakan kompensasi sirkulasi (Herrscher et al., 2014).

Penderita Gagal jantung umumnya memiliki SDB (sleep disordered breathing) didefinisikan sebagai Apnea-Hypopnea Index (jumlah peristiwa apnea dan Hypopnea /jamtidur) $\geq 5$ (Herrscher et al., 2014). Sleep Apnea obstruktif $40 \%$ ditemukan pada orang dewasa dengan gagal jantung. Central Sleep Apnea bahkan lebih sering terjadi di populasi gagal jantung. Penderita gagal jantung dan SDB memiliki waktu tidur total lebih pendek, onset untuk tertidur lebih lama dan waktu untuk terbangun setelah onset tidur, serta waktu tidur lebih pendek dibandingkan dengan mereka yang tidak gagal jantung (Liu et al., 2011 ; Thomas et al., 2008).

\section{Gambar 1.}

Hubungan Gagal jantung, Kualitas tidur dan Kualitas hidup

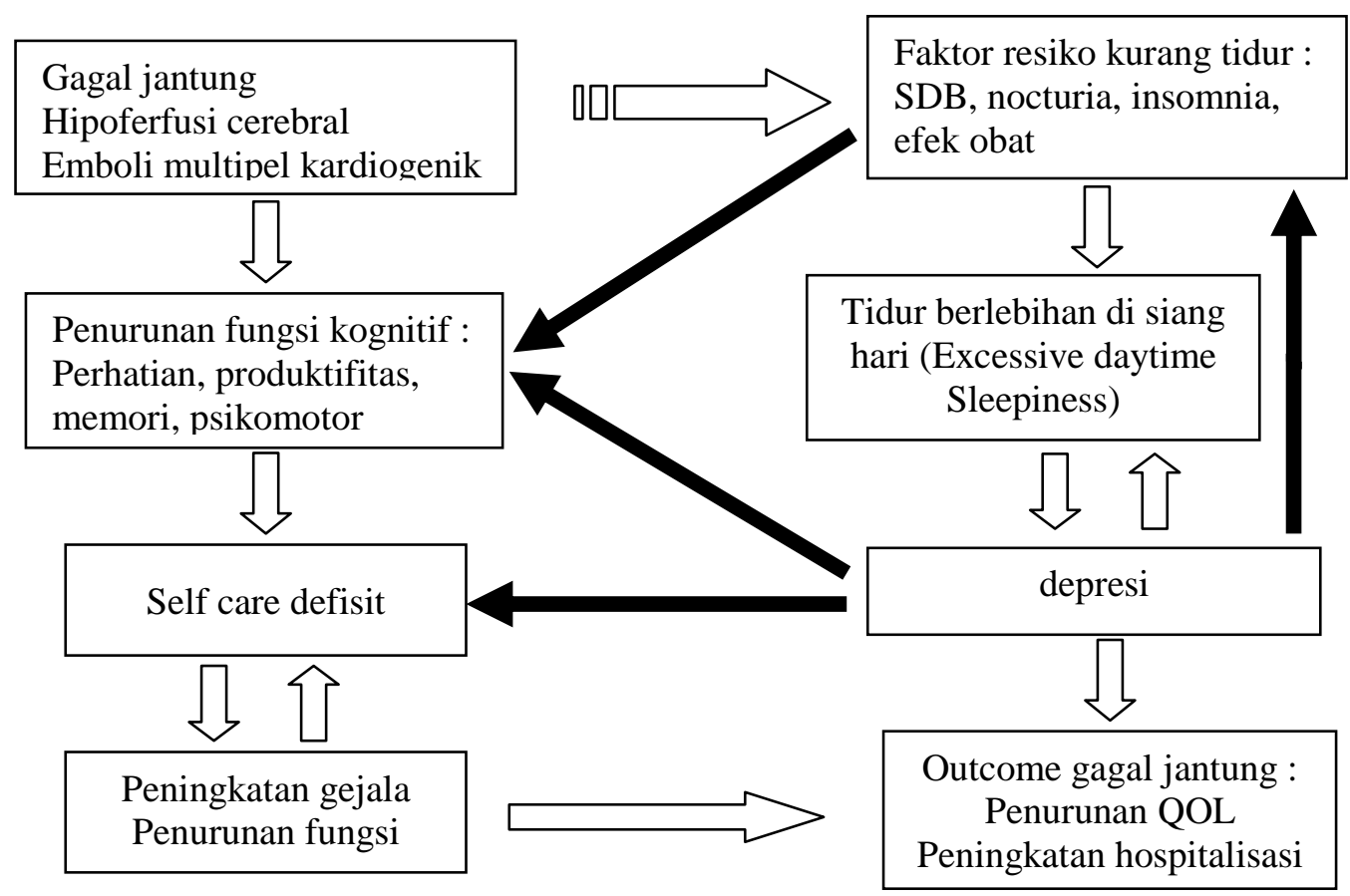

Riegel and Weaver, 2009 
Penurunan kualitas tidur pada pasien gagal jantung berdampak terhadap kualitas hidup pasien, baik secara lingkungan, fisik, sosial dan spiritualnya. Temuan memberikan bukti bahwa selain status fungsional dan kelelahan terus-menerus, kualitas hidup pasien gagal jantung berhubungan dengan tingkat keparahan SDB (Mills PJ et al., 2009). Penderita sering mengalami gejala emosi dan somatik depresi. Pikiran negatif sering dirasakan memperkuat perasaan depresi mereka ( Dekker, et al., 2009).

Dalam studinya Liu et al., 2011 menambahkan dukungan untuk bukti bahwa pasien dengan gagal jantung yang stabil, kualitas tidur yang buruk mempengaruhi kualitas hidup (Quol WHO Brief), khususnya dalam domain fisik dan psikologis, sedangkan kantuk di siang hari mempengaruhi kualitas hidup pasien pada dimensi lingkungan. Gagal jantung mengakibatkan penurunan kualitas hidup, intoleransi terhadap aktivitas, seringnya keluar masuk rumah sakit, dan peningkatan angka mortalitas.

Berbagai cara dilakukan untuk mengatasi dampak yang ditimbulkan dari penyakit gagal jantung ini baik bersifat farmakologis maupun non farmakologis. Implikasi terhadap ilmu keperawatan, diupayakan mengembangkan model terapi regimen non farmakologi, dengan mempertimbangkan aspek psikososial-spiritual (Thomas et al., 2008).

Philippe C. et al., 2005 dalam studinya menyebutkan ada peningkatan gelombang lambat dan gerakan mata cepat tidur (REM) pada pasien gagal jantung dengan penggunaan ASV (adaptive servo-ventilation), jika dibandingkan dengan dengan pemberian oksigen atau CPAP. Penggunaan ASV ini juga akan berdampak terhadap peningkatan kualitas hidup menjadi lebih tinggi pada pasien gagal jantung dengan penggunaan ASV karena ASV meningkatkan LVEF secara signifikan, hal ini menunjukkan bahwa gangguan tidur pada pasien gagal jantung lebih merasakan manfaat ASV daripada dengan CPAP (Philippe et al., 2005 ).

Selain ASV, hal lain yang perlu diupayakan pada pasien gagal jantung dengan gangguan tidur adalah pendidikan kesehatan tentang cara meningkatkan kegiatan diwaktu senggang, manajemen diri (koping mekanisme), dan keterampilan penyesuaian emosional untuk meningkatkan kualitas tidur mereka (Wang T, 2010). Pengobatan dan perawatan yang efektif dapat mengatasi masalah tidur sehingga dapat berkontribusi untuk peningkatan kualitas hidup (Redeker $\underline{\text { NS}}$, Hilkert R., 2010). Dalam penelitiannya, Suna menyebutkan bahwa olahraga yang teratur selama selama 12 minggu, dengan frekuensi latihan dua kali seminggu dapat meningkatkan kualitas tidur pasien dengan gagal jantung (Suna et al., 2015).

\section{KESIMPULAN DAN SARAN}

\section{Kesimpulan}

Penyakit gagal jantung biasanya disertai gangguan tidur yang dapat terjadi pada siang hari (tidur berkepanjangan) atau malam hari (sering terbangun) karena sesak. Hal ini berdampak terhadap penurunan kualitas hidup pasien baik dimensi fisik, psikologis, sosial dan spiritual. Perlu diupayakan penanganan baik bersifat farmakologis maupun non farmakologis. Penanganan tersebut dapat berupa :

1. Aspek farmakologis

Penggunaan ASV (adaptive servoventilation). ASV meningkatkan $\mathrm{LVEF}$ secara signifikan, hal ini menunjukkan bahwa gangguan tidur pada pasien gagal jantung lebih merasakan manfaat dengan penggunaan alat ini. 
2. Non Farmakologis
a. Pendidikan kesehatan tentang Sleep Hygiene
b. Manajemen koping bagi penderita gagal jantung
c. Pemanfaatan waktu senggang/rekreasi bagi penderita gagal jantung
d. Program olahraga secara teratur dan dibawah pengawasan ahlinya

\section{Saran}

Pengaruh penyakit gagal jantung terbukti berpengaruh terhadap kualitas tidur pasien sehingga berdampak terhadap kualitas hidupnya. Dalam penanganannya, perawat perlu mengembangkan upaya-upaya pembaharuan penatalaksanaan secara non farmakologis agar kualitas hidup pasien dengan penyakit ini semakin meningkat.

\section{DAFTAR PUSTAKA}

Henkel, M. D., Redfield, M. M., Weston, S. A., Gerber, Y., \& Roger, V. L. (2008). Death in Heart Failure: A Community Perspective. Circ Heart fail, 1, 97-91.

Herrscher, Akre, Overland, Sandvik, \& Westheim. (2014). Clinical Predictors of Sleep Apnoea in Heart Failure Outpatients. International Journal of Clinical Practice, 68(6), 728-730.

Johansson, P., Arestedt, K., Alehagen, U., Svanborg, E., Dahlström, U., \& Broström, A. (2010). Sleep Disordered Breathing, Insomnia, and Health Related Quality of Life - A Comparison Between Age and Gender Matched Elderly with Heart Failure or without Cardiovascular Disease. European Journal of Cardiovascular Nursing: Journal of the Working Group on Cardiovascular Nursing of The European Society Of Cardiology
[Eur J Cardiovasc Nurs] 9(2), 108117.

Liu, Ju-Chi, Hung, Hsiang-Lien, Shyu, YuhKae, Pei-Shan. (2011 ). The Impact of Sleep Quality and Daytime Sleepiness on Global Quality of Life in Community-dwelling Patients with Heart failure. Journal of Cardiovascular Nursing 26(2), 99-105.

Philippe, C., Stoica-Herman, M., Drouot, X., Raffestin, B., Escourrou, P., Hittinger, L., d'Ortho, M. (2005). Compliance with and Efficacy of Adaptive Servoventilation (ASV) versus Continuous Positive Airway Pressure (CPAP) in the Treatment of Cheyne-Stokes Respiration in Heart Failure Over a Six Month Period. Heart.

Redeker, N., \& Hilkert, R. (2010 ). Sleep and Quality of Life in Stable Heart Failure. J Adv Nurs., 66(8), 17301740.

Redeker, N., Jeon, S., Muench, U., Campbell, D., Walsleben, J., \& Rapoport, D. (2010). Insomnia Symptoms and Daytime Function in Stable Heart Failure. Sleep [Sleep] 33(9), 12101216.

Suna, Mudge, Stewart, Marquart, O'Rourke, $\&$ A;, S. (2015). The Effect of $a$ Supervised Exercise Training Programme on Sleep Quality in Recently Discharged Heart Failure Patients. European Journal Of Cardiovascular Nursing, 14 (3), 198205.

Thomas, S. A., Chapa, D. W., Friedmann, E., Durden, C., Ross, A., Lee, M. C. Y., \& Lee, H.-J. (2008). Depression in Patients with Heart Failure: Prevalence, Pathophysiological 
Kualitas Tidur Pasien Gagal Jantung dan Penanganannya (Inggriane Puspita Dewi)

Mechanisms, and Treatment. Crit Care Nurse 28, 40-45.

Wang, T., Lee, S., Tsay, S., \& Tung, H. (2010). Factors Influencing Heart
Failure Patients Sleep Quality. Journal of Advanced Nursing 66(8), 1730-1740. 